\title{
Effect of Cobalt-Chromium- Molybdenum Implant Surface Modifications on Biofilm Development of S. aureus and S. epidermidis
}

\author{
Astrid H. Paulitsch-Fuchs ${ }^{1,2}$, Benjamin Bödendorfer ${ }^{1}$, Lukas Wolrab ${ }^{1}$, Nicole Eck ${ }^{3}$, \\ Nigel P. Dyer ${ }^{4}$ and Birgit Lohberger ${ }^{3 *}$
}

${ }^{1}$ Biomedical Sciences, University of Applied Sciences Carinthia, Klagenfurt, Austria, ${ }^{2}$ Diagnostic and Research Institute of Hygiene, Microbiology and Environmental Medicine, Medical University of Graz, Graz, Austria, ${ }^{3}$ Department of Orthopaedics and Trauma, Medical University of Graz, Graz, Austria, ${ }^{4}$ Bioinformatics Research Technology Platform, University of Warwick, Coventry, United Kingdom

OPEN ACCESS

Edited by: Fany Reffuveille, Université de Reims

Champagne-Ardenne, France

Reviewed by:

Kuntaman Kuntaman, Airlangga University, Indonesia

Markus Bischoff,

Saarland University Hospital, Germany

${ }^{*}$ Correspondence:

Birgit Lohberger birgit.lohberger@medunigraz.at

Specialty section: This article was submitted to Biofilms,

a section of the journal Frontiers in Cellular and Infection Microbiology

Received: 16 December 2021 Accepted: 04 February 2022 Published: 01 March 2022

Citation:

Paulitsch-Fuchs AH, Bödendorfer B, Wolrab L, Eck N, Dyer NP and Lohberger B (2022) Effect of Cobalt-Chromium-Molybdenum Implant Surface Modifications on Biofilm Development of

S. aureus and S. epidermidis. Front. Cell. Infect. Microbiol. 12:837124.

doi: 10.3389/fcimb.2022.837124
Periprosthetic infections are an eminent factor in patient care and also having significant economic implications. The number of biofilm-infection related replacement surgeries is increasing and will continue to do so in the following decades. To reduce both the health burden of the patients and the costs to the healthcare sector, new solutions for implant materials resistant to such infections are necessary. This study researches different surface modifications of cobalt-chromium-molybdenum (CoCrMo) based implant materials and their influence on the development of biofilms. Three smooth surfaces (CoCrMo, CoCrMo TiN, and CoCrMo polished) and three rough surfaces (CoCrMo porous coated, CoCrMo cpTi, and CoCrMo TCP) are compared. The most common infectious agents in periprosthetic infections are Staphylococcus aureus and Coagulasenegative staphylococci (e.g., Staphylococcus epidermidis), therefore strains of these two species have been chosen as model organisms. Biofilms were grown on material disks for $48 \mathrm{~h}$ and cell number, polysaccharide content, and protein contend of the biofilms were measured. Additionally, regulation of genes involved in early biofilm development ( $S$. aureus icaA, icaC, fnbA, fnbB, clfB, atl; $S$. epidermidis atlE, aap) was detected using RT-qPCR. All results were compared to the base alloy without modifications. The results show a correlation between the surface roughness and the protein and polysaccharide content of biofilm structures and also the gene expression of the biofilms grown on the different surface modifications. This is supported by the significantly different protein and polysaccharide contents of the biofilms associated with rough and smooth surface types. Additionally, early phase biofilm genes (particularly ica $A$, icaC, and aap) are statistically significantly downregulated compared to the control at $48 \mathrm{~h}$ on rough surfaces. CoCrMo TiN and polished CoCrMo were the two smooth surface modifications which performed best on the basis of low biofilm content. 


\section{INTRODUCTION}

Due to a general increase in life expectancy, improved surgical techniques and medical care, the demand for implants (e.g., joint replacement prosthesis) has increased greatly over recent decades. Although new materials or surface modifications for implants are constantly being developed, the struggle with periprosthetic infections is far from coming to an end. As an example, predictions for the US (compared to 2014) and Germany (compared to 2016) show an increase in primary total knee arthroplasty (TKA) by 2030 from 680,000 by $147 \%$ (Sloan et al., 2018) and from $\sim 170,000$ by between 8 and $49 \%$ (Rupp et al., 2020), respectively. Periprosthetic infections have an incidence of approximately $1-4 \%$ after primary TKA (Phillips et al., 2006). The incidence rate for a periprosthetic infection following a TKA replacement has been reported to be approximately $0.5 \%$ after 1 year, $0.8 \%$ after 5 years, and $1.4 \%$ after 10 years (Tsaras et al., 2012), with cost per patient associated with TKA replacement of up to 30,000 USD (Palsis et al., 2018).

Those periprosthetic infections can be caused by a number of different organisms, most of which are bacteria. In most cases a bacterial infection forms a biofilm on the surface of the implant which makes it even harder to treat. In a 2020 literature review on the topic of biofilms in periprosthetic infections Shoji and Chen (2020) reported a prevalence of Staphylococcus aureus in such infections of $21-43.6 \%$ followed by $20-31 \%$ Coagulasenegative Staphylococcus. Biofilm building Staphylococcus species have a large number of attributes allowing them to avoid host defenses and antibiotic treatments. The extracellular polymeric substances (EPS), also called extracellular matrix (ECM), build a physical barrier for transport of chemicals (Singh et al., 2010; Idrees et al., 2021) and immune-cells (Zimmerli et al., 1984) and hold the biofilm structure together. In addition, quorum sensing (Kavanaugh and Horswill, 2016; Kim et al., 2017), higher mutation frequencies (Ryder et al., 2012), and dormant cells (Venter et al., 2017; Lamret et al., 2020; Shoji and Chen, 2020) contribute to the pathogenicity of those strains.

Because treatment of already established biofilms is so difficult, the development of surfaces which are less favorable for the bacteria to attach to in the first place is an ongoing research topic. Cobalt-chromium-molybdenum (CoCrMo) based implants are regularly used not only for total joint replacement but also in dentistry (Chen and Thouas, 2015). The CoCrMo alloy has excellent biocompatibility and mechanical properties, which makes it the preferred material for knee and ankle replacements (Chen and Thouas, 2015). Physical and chemical surface modifications of metallic implant materials aim to improve their surface charge, wettability, topography and chemistry (Munir et al., 2020) in order to improve their osseointegration abilities and in the same time lessen the number of biofilm infections. These modifications can be achieved by mechanical treatment of the surfaces like polishing processes and numerous coating methods like plasma spraying, physical vapor deposition, cathodic arc deposition, and sintering (Munir et al., 2020). For this study five surface modifications have been applied to a casted CoCrMo base alloy: titanium nitride (TiN), mechanical polishing, porous coating, commercially pure titanium coating (cpTi), and a coating with tricalcium phosphate (TCP). Two bacterial species, S. aureus and S. epidermidis, were used as model organisms to monitor biofilm development after $48 \mathrm{~h}$ of incubation on the different alloy surfaces. Total cell count, protein and polysaccharide content of the biofilms were measured and data on biofilm associated gene expression was collected. The aim of the study is to understand the influence of the different CoCrMo surface modifications on the biofilm formation of $S$. aureus and S. epidermidis.

\section{MATERIAL AND METHODS}

\section{CoCrMo Surface Modifications}

All materials tested in this study were manufactured by Implantcast GmbH (Buxtehude, Germany) and were produced in a disc shape with a thickness of $1 \mathrm{~mm}$ and a diameter of $14 \mathrm{~mm}$ using a precision casting process. Gamma irradiation was used for sterilizing all materials described hereafter. Special coatings were produced and applied by DOT Ltd (Rostock, Germany). The CoCroMo casting alloy is composed of 28.5$29.5 \% \mathrm{Cr}, 5.75-6.25 \% \mathrm{Mo}$, less than $1 \%$ each of $\mathrm{Ni}, \mathrm{Fe}, \mathrm{C}, \mathrm{Si}, \mathrm{Mn}$, $\mathrm{W}, \mathrm{P}, \mathrm{N}, \mathrm{Al}, \mathrm{Ti}$; and $\mathrm{Co}(\sim 61-64 \%)$ making up the balance. This lies well within the specifications for this material given by the ISO 5832-3 for CoCrMo casting alloy for surgical implants (ISO 5832-3, 2016). Mechanical properties of the base CoCrMo alloy were tested according to ISO 6892-1 (2019) and are given as: tensile yield point $R_{p 0.2} \geq 450$ megapascal (MPa), tensile strength $R_{m} \geq 665 \mathrm{MPa}$ and elongation at fracture $\mathrm{A} \geq 8 \%$. Titanium nitride (TiN) modified alloy surfaces show better properties in terms of biocompatibility, wettability, surface roughness, friction coefficient, corrosion resistance, minimized wear and increased temperature resistance; the TiN coating also leads to a reduced release of cobalt and chromium ions (Van Hove et al., 2015; Thomas et al., 2016). The coating of the discs was achieved by cathodic arc deposition. This technique is frequently used to synthesize extremely hard films for protecting the surfaces of materials. For the deposition a TiN target with $99.4 \%$ titanium and less than $0.25 \%$ each of $\mathrm{Fe}, \mathrm{O}, \mathrm{C}, \mathrm{N}$ and $\mathrm{H}$ (all according to ISO 5832-2 (2018)). The coating thickness was $5.5 \pm 1.5 \mu \mathrm{m}$, the adhesive tensile strength $\geq 22 \mathrm{MPa}$ and the layer roughness $<0.05$ $\mu \mathrm{m}$. On top of the TiN layer an additional layer of $\geq 0.02 \mu \mathrm{m}$ gold and cobalt $(\mathrm{AuCo}$; with a maximum percentage of $0.2 \pm 0.02 \%$ cobalt) was applied using a PVD-DC-Magnetron sputter. The density of the AuCo layer was $19.32 \mathrm{~g} / \mathrm{cm}^{3}$, the specific electrical resistance was $2.35 \mu \Omega \cdot \mathrm{cm}$ and the tensile strength is sufficient to prevent delamination of the coating when using an adhesive film strip-test. Highly polished CoCrMo alloys are commonly used, where the increased surface smoothness is associated with improved corrosion and wear properties (Davis, 2003). The porous coating was applied on the base material using sintering. In this process three layers of $250-355 \mu \mathrm{m}$ diameter balls were applied on the material discs resulting in a coating thickness of $700-1,060 \mu \mathrm{m}$. Porosity of the coating was $30-40 \%$, its tensile strength $\geq 34.5 \mathrm{MPa}$ and its shear strength $\geq 20 \mathrm{MPa}$. 
The porous structure allows bone cells to "penetrate" into the implant, leading to a reduced rejection reaction. However, these pores also provide the bacterial cells with an increased surface area for adherence (Shoji and Chen, 2020; Idrees et al., 2021). The commercially pure titanium (cpTi) coating with a layer thickness of $300 \pm 50 \mu \mathrm{m}$ was sprayed onto the disc surfaces using a vacuum plasma spray (VPS). The resulting coating had a porosity of $30 \pm 10 \%$, an average roughness of $50 \pm 15 \mu \mathrm{m}$, a tensile strength of $\geq 22 \mathrm{MPa}$ and a shear strength of $\geq 20 \mathrm{MPa}$. cpTi covered materials show an improved osteogenic differentiation potential (Lohberger et al., 2020a), since the given porous upper layer in combination with the increase in surface energy offers the bone cells an optimal structure for adhesion (Geetha et al., 2009). Tricalcium phosphate coating (TCP, Bonit ${ }^{\circledR}$ ) led to a deposited layer of $20 \pm 10 \mu \mathrm{m}$ thickness and to a tensile strength of $\geq 15 \mathrm{MPa}$ (ISO 13779-2, 2018). TCP consist of $70 \%$ brushite $\left(\mathrm{CaHPO}_{4} 2 \cdot \mathrm{H}_{2} \mathrm{O}\right)$ and $30 \%$ hydroxyapatite $\left(\mathrm{Ca}_{5}\left(\mathrm{PO}_{4}\right)_{3} \mathrm{OH}\right)$. The calcium phosphate provides an advantage for osteoinduction to its surface as its bioactivity is highly similar to that of bone material and it thus facilitates improved cell growth and cytocompatibility (Dantas et al., 2018).

\section{Scanning Electron Microscopy (SEM)}

SEM investigations were performed on a FEI Quanta 250 FEG (Thermo Fisher Scientific, Hillsboro, OR) under high vacuum conditions and $20 \mathrm{kV}$ high tension. The micrographs were recorded in secondary electron (SE) mode with the EverhartThornley detector. The disc surfaces of the material were sputter coated with a gold layer $(10 \mathrm{~nm})$ to provide adequate electrical conductivity. The energy-dispersive X-ray spectroscopy (EDX) data collection measurements took $60 \mathrm{~s}$ each at $20 \mathrm{kV}$ high tension and a Spotsize of 4.5 with a $30 \mathrm{~mm}^{2}$ Octane Elect Plus Silicon Drift Detector (EDAX Ametek, NJ, USA) and the APEX Standard Software (V1.3.1, 07/2019) was used.

\section{Bacterial Cultures}

For each experimental run, one overnight culture was prepared for each S. aureus subsp. aureus strain Newman D2C (ATCC 25904, Wesel, Germany; also referred to as NCTC 10833 or S. aureus subsp. aureus Rosenbach) and S. epidermidis (ATCC 14990, Wesel, Germany; also referred to as NCTC 11047). Luria-Bertani broth (LB broth) containing $10 \mathrm{~g} / \mathrm{L}$ tryptone, $5 \mathrm{~g} / \mathrm{L}$ yeast extract (both Carl Roth), and $5 \mathrm{~g} / \mathrm{L}$ sodium chloride (Merck, Darmstadt, Germany) was used as growth medium. Per strain one CRYOBANK ${ }^{\circledR}$ pearl (MAST Group, Reinfeld, Germany) was inoculated into $100 \mathrm{ml} \mathrm{LB}$ and cultures were incubated at $37^{\circ} \mathrm{C}$ at $90 \mathrm{rpm}$.

\section{Biofilm Assay}

The material discs (4 discs per material, all 6 materials) were placed in 24-well untreated clear polystyrene plates (Corning ${ }^{\circledR}$, Wiesbaden, Germany) as shown in Figure 1. The bacterial cells from the overnight culture were distributed into $1.5 \mathrm{ml}$ Eppendorf tubes and collected by centrifugation (14,000 rpm, $2 \mathrm{~min}$ ). The supernatant was discarded and the cells where resuspended and washed in $1.5 \mathrm{ml}$ of phosphate buffered solution (PBS). Cells were centrifuged again (14,000 rpm, $2 \mathrm{~min}$ ) and then freshly inoculated into LB broth. The cell number was adjusted to $1.5 \times 10^{8} \mathrm{CFU} / \mathrm{ml}$ in $\mathrm{LB}$ broth and $1.5 \mathrm{ml}$ of the adjusted cell solution was added to each well. The plate was then sealed with a Breathe Easy ${ }^{\circledR}$ sealing membrane (Merck, Darmstadt, Germany) and incubated for $48 \mathrm{~h}$ at $37^{\circ} \mathrm{C}$ and $90 \mathrm{rpm}$. A total of 4 discs per material and species were prepared for each of the 21 experimental runs (biological replicates). Growth controls (bacteria without discs) and sterile controls (sterile LB media on material discs) were run in parallel for every experimental run.

\section{Biofilm Processing}

For the collection of the samples the medium was first gently removed without disturbing the biofilm and $1.5 \mathrm{ml}$ PBS was

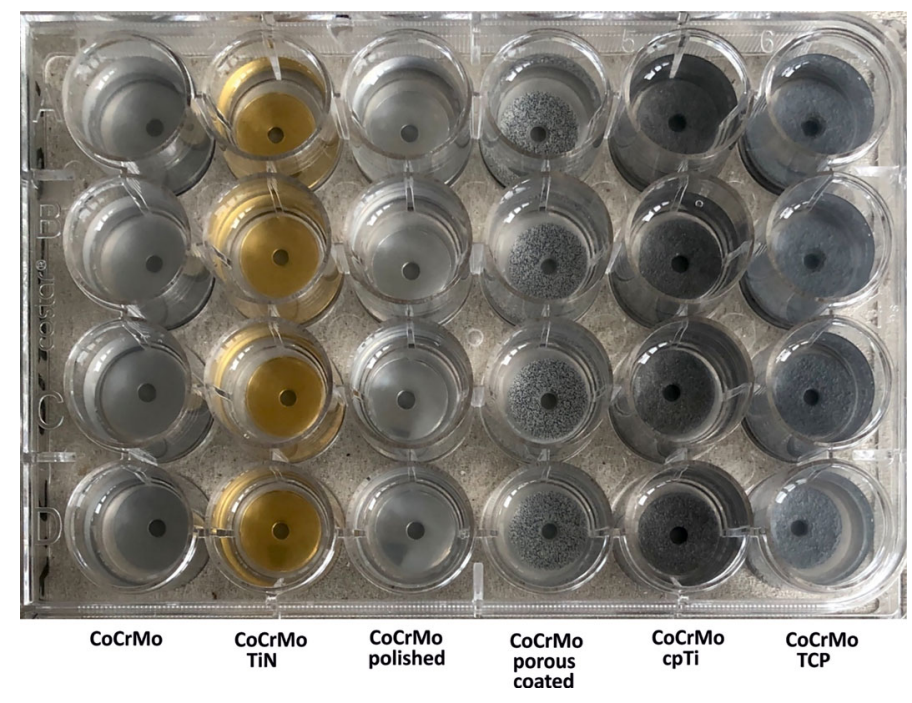

FIGURE 1 | Cell culture plate with the different alloy discs. 
added into each well. The discs were picked up using tweezers, shaken within the PBS and the biofilm from all sides of the disk was scraped into a fresh PBS filled well with a mini cell scraper (Biotium, Freemont, CA, USA). At the end of the process the scraper was vigorously rotated in the well to ensure that no biofilm residues remained on the scraper. The content of two wells per material was pooled in a $3.5 \mathrm{ml}$ tube and vortexed until no biofilm parts were visible. This step took up to $30 \mathrm{~min}$ on the vortexer in continuous mode and random samples were checked microscopically to ensure that there were no more biofilm parts in the samples before further processing. The growth controls were re-suspended in the medium and then transferred into $3.5 \mathrm{ml}$ tubes; the sterile controls were also pipetted into the individual collection tubes directly. The resulting $3 \mathrm{ml}$ sample volume (per biofilm pool and controls) was divided to provide the volumes needed for the four different measurement protocols (see below). Samples for genetic analysis were frozen at $-80^{\circ} \mathrm{C}$ until further processing, all protein and polysaccharide samples were stored in the fridge at $4^{\circ} \mathrm{C}$ for no longer than $24 \mathrm{~h}$ before analysis, flow cytometry was performed directly after biofilm processing and samples were kept at $4^{\circ} \mathrm{C}$ until loading onto the instrument.

\section{Polysaccharide Quantification}

Polysaccharides of the total biofilm were quantified using an adapted version of an sulfuric acid phenol extraction method (Cuesta et al., 2003). Approximately $250 \mu \mathrm{l}$ of each sample, $250 \mu \mathrm{l}$ 99.5\% phenol, and $750 \mu \mathrm{l} 95-98 \%$ sulfuric acid were added to heat-resistant glass tubes, sealed with aluminum foil (not air tight) and vortexed for at least $20 \mathrm{~s}$. Incubation took place in a water bath at $100^{\circ} \mathrm{C}$ for $10 \mathrm{~min}$. In an additional water bath samples were cooled to $25^{\circ} \mathrm{C}$, vortexed again and $250 \mu \mathrm{l}$ was transferred into uncoated U-bottom 96-well plates (BRAND ${ }^{\circledR}$, Sigma-Aldrich, Darmstadt, Germany). Absorbance was read at $490 \mathrm{~nm}$ in the Multiskan Sky Microplate Spectrophotometer (Thermo Fisher Scientific). Each sample was measured twice and the statistical mean was compared to a standard glucose curve (Merck; 0-1.5 $\mu \mathrm{g} / \mathrm{ml}$ ).

\section{Protein Quantification}

The 'Pierce ${ }^{\mathrm{TM}}$ BCA Protein Assay Kit' (Thermo Fisher Scientific, Waltham, MA, USA) was used to measure the total protein content of the biofilms. The $562 \mathrm{~nm}$ absorbance values of the samples ( $25 \mu \mathrm{l}$ sample in $200 \mu \mathrm{l}$ working reagent from the kit) in uncoated U-bottom 96-well plate were read on a Multiskan Sky Microplate Spectrophotometer. Each sample was measured twice. The standard curve was prepared with bovine serum albumin (BSA, supplied with the BCA kit; 0-2,000 $\mu \mathrm{g} / \mathrm{ml}$, Thermo Fisher Scientific, Waltham, MA, USA) and the arithmetic mean of the duplicate measurement was compared to the curve.

\section{Live Dead Assay}

Flow cytometric cell counts were performed applying the 'LIVE/ DEAD ${ }^{\circledR}$ BacLightTM Viability Kit (Invitrogen, Carlsbad, CA, USA) for microscopy and quantitative assays'. The Syto $9^{\circledR}$ and propidium iodide dye mixes were freshly prepared for each measurement in a ratio of 1:1. Per sample, $1 \mathrm{ml}$ was stained with $1 \mu \mathrm{l}$ of the dye mixture and incubated in the dark for $15 \mathrm{~min}$ at room temperature and $100 \mu \mathrm{l}$ per sample were analyzed on a Cyflow ${ }^{\circledR}$ Cube 6 flow cytometer (Sysmex Europe GmbH, Norderstedt, Germany). The flow rate was set at $2 \mu \mathrm{l} / \mathrm{s}$ and a $488 \mathrm{~nm}$ laser was used. All samples were measured twice and to avoid signal carryover, cleaning was performed between all measurements.

\section{Statistics}

SPSS (IBM, version 25) was used for statistical analyses of protein, polysaccharide, and flow cytometry data. The data was found to be non-Gaussian (Kolmogorov-Smirnov test with Lilliefors correction). Consequently, the Kruskal-Wallis $\mathrm{H}$ test was applied. Statistical differences were tested in a pairwise comparison format and the Bonferroni correction for the Kruskal-Wallis test was used.

\section{RNA Isolation}

RNA from the samples of three independent experimental runs (3 biological replicates) was extracted with the Monarch ${ }^{\circledR}$ Total RNA Miniprep Kit (New England BioLabs, Ipswich, MA, USA). The enzymatic approach step of the manufacturer's protocol was adapted: additionally, $0.1 \mathrm{mg} / \mathrm{ml}$ lysostaphin (Sigma-Aldrich, Darmstadt, Germany) was added to the $3 \mathrm{mg} / \mathrm{ml}$ lysozyme which was provided with the kit. Samples were incubated for $25 \mathrm{~min}$ at $350 \mathrm{rpm}$ at $37^{\circ} \mathrm{C}$ before carrying out the rest of the protocol according to the guidelines. Final elution volume was $30 \mu \mathrm{l}$ per sample.

\section{RT-qPCR}

Using the iScript cDNA Synthesis Kit (BioRad Laboratories Inc., Veenendal, The Netherlands) $1 \mu \mathrm{g}$ RNA was reverse-transcribed with a mixture of oligo (dT) and random hexamer primers. The samples were amplified with the SsoAdvanced Universal SYBR Green Supermix and subsequently measured on a CFX96 Touch (BioRad Laboratories Inc.), as described elsewhere (Lohberger et al., 2020b). A standard 3-step PCR temperature protocol was used with an annealing temperature of $60^{\circ} \mathrm{C}$ followed by a melting curve protocol to confirm a single gene-specific peak and to detect primer dimerization. The $\Delta \Delta \mathrm{Ct}$ method was applied for the calculation of the relative quantification of expression levels by means of the geometric mean of the internal control (16s rRNA gene for $S$. aureus and also for $S$. epidermidis; for primer sequences see Table 1). The expression levels $(\mathrm{Ct})$ of the target genes were normalized to the reference genes $(\Delta \mathrm{Ct})$. The $\Delta \Delta \mathrm{Ct}$ value was calculated using the difference between the $\Delta \mathrm{Ct}$ value of the test sample and the $\Delta \mathrm{Ct}$ of the control sample. The final expression ratio was expressed as $2 \Delta \Delta \mathrm{Ct}$ (Livak and Schmittgen, 2001). Primers used for RTqPCR were purchased from Eurofins Genomics (Ebersberg, Germany) and primer sequences are listed in Table $\mathbf{1 .}$

\section{RESULTS}

\section{Material Surface Characteristics}

The surface characteristics of the different modifications to the CoCrMo alloy discs have been studied using both SEM and EDX 
TABLE 1 | Primes used in RT-q-PCR.

\begin{tabular}{|c|c|c|c|c|}
\hline Strain & Gene & Primer forward & Primer reverse & Reference \\
\hline \multirow[t]{7}{*}{ S. aureus } & $i c a A$ & 5-GAGGTAAAGCCAACGCACTC-3 & 5-CCTGTAACCGCACCAAGTाT-3 & Atshan et al. (2013) \\
\hline & icaC & 5-CTTGGGTATTGCACGCATT-3 & 5-GCAATATCATGCCGACACCT-3 & Atshan et al. (2013) \\
\hline & $f n b A$ & 5-AAATTGGGAGCAGCATCAGT-3 & 5-GCAGCTGAATTCCCATITTC-3 & Atshan et al. (2013)) \\
\hline & 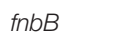 & 5-ACGCTCAAGGCGACGGCAAAG-3 & 5-АCСТTCTGCATGACCTTCTGCACCT-3 & Atshan et al. (2013) \\
\hline & clfB & 5-AACTCCAGGGCCGCCGGTTG-3 & 5-ССTGAGTCGСTGTCTGAGCCTGAG-3 & Atshan et al. (2013) \\
\hline & atl & 5-TाTGGTTCCAGAGCCAGAC-3 & 5-TTGGGTTAAAGAAGGCGATG-3 & Yin et al. (2018) \\
\hline & $16 S$ rRNA & 5'-GGGACCCGCACAAGCGGTGG-3' & 5'-GGGTTGCGCTCGTTGCGGGA-3' & Atshan et al. (2013) \\
\hline \multirow[t]{3}{*}{ S. epidermidis } & atle & 5-TGTCCTGCTITCACGTATGA-3 & 3-TCTITGGAATTGGTGCATाT-5 & Patel et al. (2012) \\
\hline & aар & 5-TGATCGGATCTCCATCAACT-3 & 3-AAGGTAGCCAAGAGGACGTT-5 & Patel et al. (2012) \\
\hline & $16 S$ rRNA & 5TACACACCGCCCGTCACA & 5'CTTCGACGGGCTAGCTCCAAAT & Vandecasteele et al. (2001) \\
\hline
\end{tabular}

analyses. The topographic characteristics of materials are well known to have a substantial influence on the adhesive properties of bacterial cells and therefore the microscopic investigation is helpful for understanding the data collected in this study. While the base alloy CoCrMo without modifications shows a rather smooth surface at $\times 100$ magnification (Figure 2A), a closer look $(\times 10,000$, Figure 2A inlay) reveals only some cracks and some unevenness and the surface modification with TiN and the polished surface are even smoother. However, the porous coated surface and the cpTi and TCP covered surfaces show very distinct topographic characteristics. While the porous coated surface consists of a thick layer of evenly distributed (Figure 2D) and rather smooth balls (surface of the ball in the inlay of Figure 2D), the cpTi layer is rougher (Figure 2E) and the higher magnification also reveals that this characteristic is also true at the small $\mu \mathrm{m}$ range (inlay Figure 2E). Very distinctly different from the rest, the TCP layer forms sharp crystalline structures protruding from the alloy surface (Figure 2F).
Looking at the surface characteristics, the surfaces can be categorized as either smooth (CoCrMo, CoCrMo TiN, and CoCrMo polished) or rough (CoCrMo porous coated, CoCrMo cpTi, and CoCrMo TCP).

The corresponding EDX data supports the material descriptions given in the material and methods section, showing the elemental composition of the materials as spectrograms and in weight and atom percentages (Figures 3AE; data not available for TCP).

\section{Polysaccharide Content}

As all Staphylococci can produce polysaccharides in their EPS when forming biofilms (Arciola et al., 2015), an approach that is often applied is to break the polysaccharides down into monosaccharides and measure the content compared to a glucose standard curve (Cuesta et al., 2003). Following this procedure, we found (Table 2 and Figure 4) that the biofilms grown on the smooth surfaces (CoCrMo, CoCrMo TiN, and
A

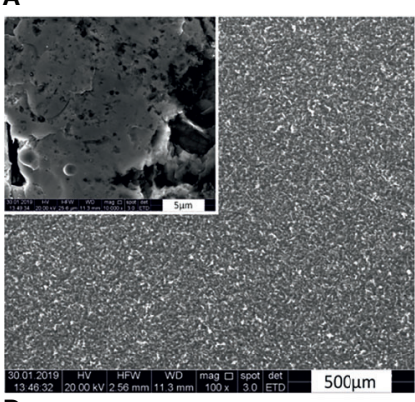

D

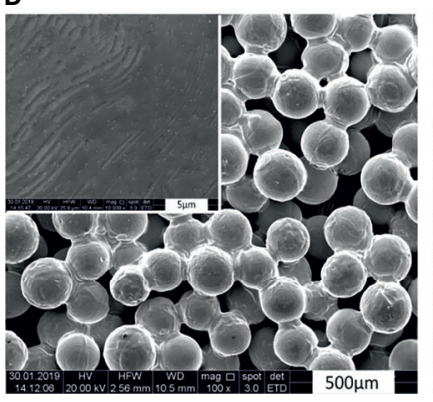

B

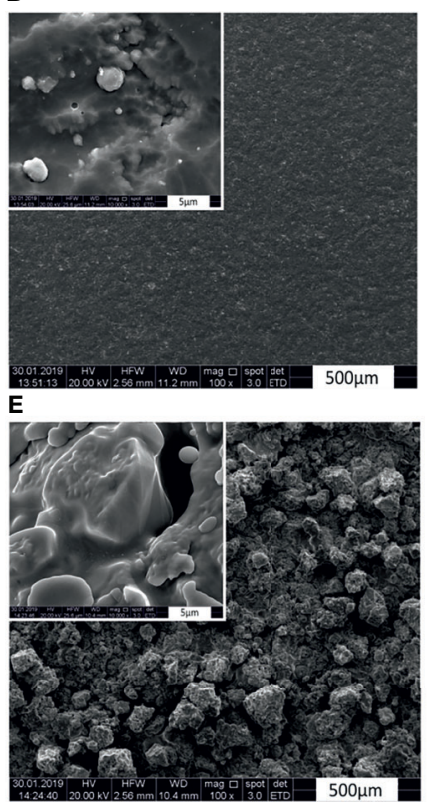

C

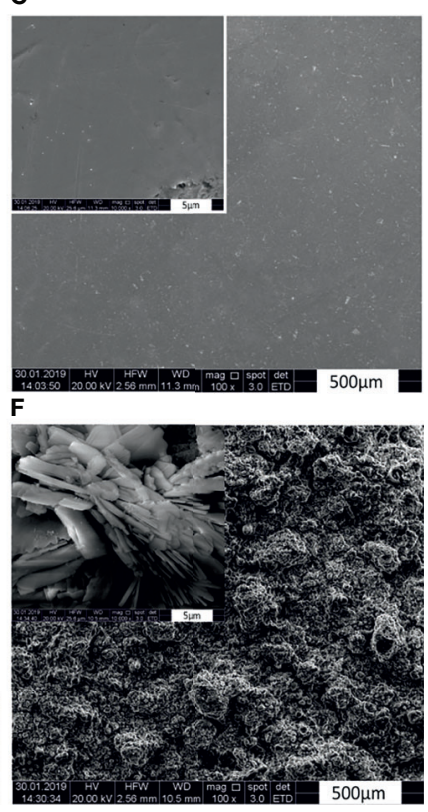

FIGURE 2 | Scanning electron microphotographs of CoCrMo and the different surface modifications. Magnification factor $\times 100$, and inlays $\times 10,000$. (A) CoCrMo; (B) CoCrMo TiN; (C) CoCrMo polished; (D) CoCrMo porous coated; (E) CoCrMo cpTi, (F) CoCrMo TCP. 
CoCrMo polished) show a tendency to form less polysaccharide in their EPS compared to those grown on the rough surfaces (CoCrMo porous coated, CoCrMo cpTi, and CoCrMo TCP). The highest polysaccharide levels for $S$. aureus were measured in biofilms grown on CoCrMo cpTi discs with a mean value of $5.69 \pm$ $1.5 \mu \mathrm{g} / \mathrm{ml}$, the lowest values were measured in biofilms from the CoCrMo TiN and the CoCrMo polished discs with $4.15 \pm 0.71 \mu \mathrm{g} /$ $\mathrm{ml}$ and $\pm 0.8 \mu \mathrm{g} / \mathrm{ml}$ respectively (Table 2 ). S. epidermidis biofilms showed the highest polysaccharide values on CoCrMo cpTi (6.21 \pm $3.06 \mu \mathrm{g} / \mathrm{ml})$ and the lowest ones on CoCrMo TiN $(4.11 \pm 0.78 \mu \mathrm{g} /$ $\mathrm{ml}$ ) (Table 2). In both species the polysaccharide content of the biofilms grown on CoCrMo porous coated, CoCrMo cpTi and CoCrMo TCP shows a highly significant difference $(\mathrm{p}<0.001)$ compared to that of the CoCrMo alloy itself (Figure 4). Table 3 summarizes all group comparisons (each alloy compared to each) where a clear statistical difference can be seen whenever a smooth surface is compared to a rough surface. One exception here is the comparison of S. epidermidis biofilms on CoCrMo porous coated with biofilms from CoCrMo cpTi surfaces where, in the overall group comparison (adjusted p-value for multiple comparisons), no statistical difference is found (adj. $\mathrm{p}$-value $=0.055$ ). However, if the multiple comparison is disregarded, which is possible in a direct comparison of the two groups in question, the difference becomes significant again $(\mathrm{p}=0.004)$. This leads to the conclusion that the CoCrMo porous coated surface is the best performer (smallest biofilm content) in the rough surface group. Additionally, in the

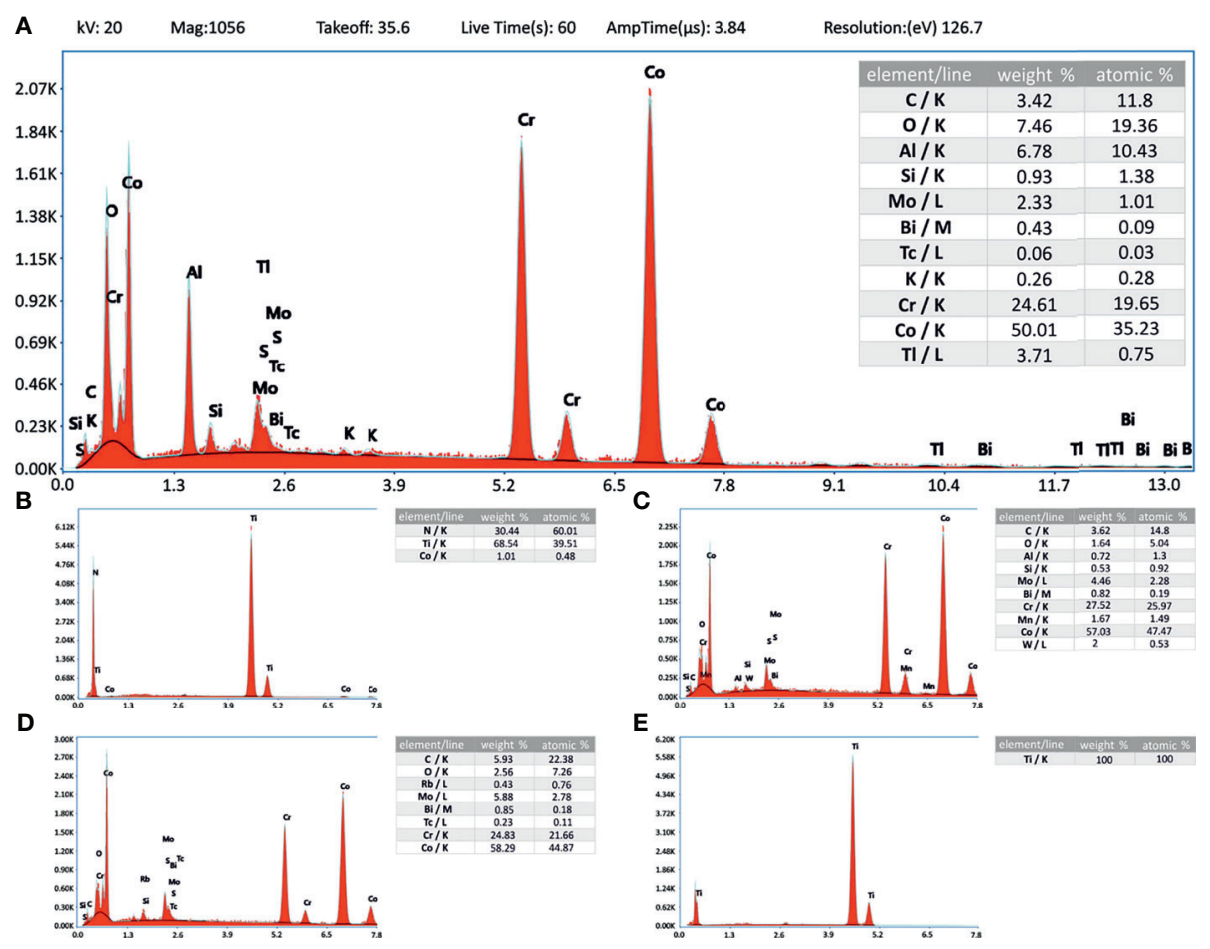

FIGURE 3 | Energy-dispersive X-ray analysis. Inlay tables showing the elemental composition related to the energy level (K-, L-and M-line). Instrument values are given in panel (A) and apply also to (B-E). (A) CoCrMo; (B) CoCrMo TiN; (C) CoCrMo polished; (D) CoCrMo porous coated; (E) CoCrMo cpTi.

TABLE 2 | Mean, minimum and maximum values and standard deviations (SD; 95\% confidence interval) of protein and polysaccharide measurements.

\begin{tabular}{|c|c|c|c|c|c|c|c|c|}
\hline \multirow[t]{2}{*}{ Alloy } & \multicolumn{4}{|c|}{ S. aureus } & \multicolumn{4}{|c|}{ S. epidermidis } \\
\hline & $\begin{array}{c}\text { mean [min; max] } \\
(n=42)\end{array}$ & SD & $\begin{array}{c}\text { mean [min; max] } \\
\quad(n=44)\end{array}$ & SD & $\begin{array}{c}\text { mean [min; max] } \\
\quad(n=42)\end{array}$ & SD & $\begin{array}{c}\text { mean }[\text { min; max] } \\
\quad(n=44)\end{array}$ & SD \\
\hline CoCrMo & 124.56 [68.10; 214.10] & 34.89 & $4.46[3.47 ; 7.74]$ & 0.91 & $101.95[36.5 ; 203.5]$ & 34.78 & $4.23[3.25 ; 6.47]$ & 0.75 \\
\hline CoCrMo TiN & $97.55[55.40 ; 148.60]$ & 28.12 & $4.15[3.27 ; 5.82]$ & 0.71 & $77.65[26.7 ; 162.4]$ & 32.12 & $4.11[3.15 ; 7.13]$ & 0.78 \\
\hline CoCrMo cpTi & $202.87[121.20 ; 269.70]$ & 35.5 & $5.69[4.17 ; 9.01]$ & 1.5 & $190.23[115.1 ; 341.1]$ & 42.79 & $6.21[3.76 ; 22.69]$ & 3.06 \\
\hline CoCrMo TCP & $240.08[153.10 ; 455.60]$ & 58.6 & $5.24[3.95 ; 8.53]$ & 1.14 & $215.51[113.3 ; 356.6]$ & 56.42 & $5.27[3.67 ; 8.51]$ & 1.19 \\
\hline
\end{tabular}



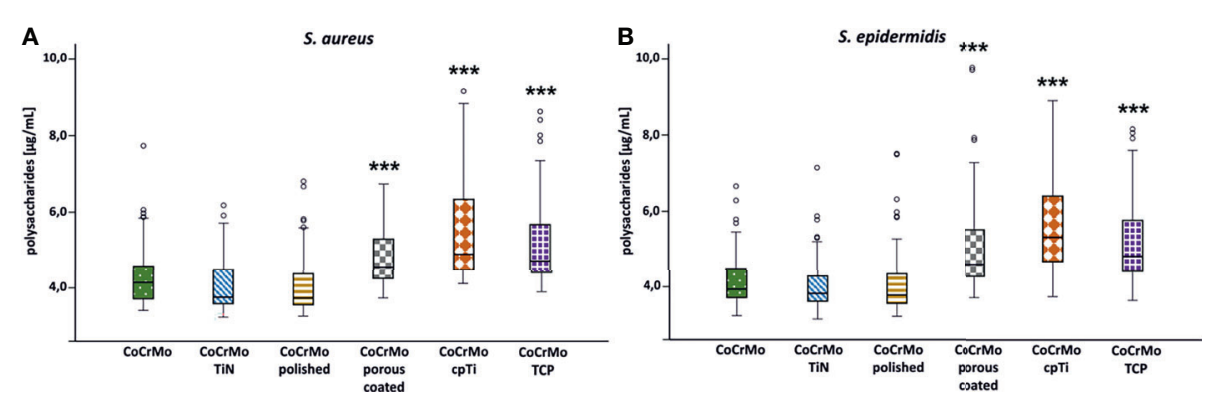

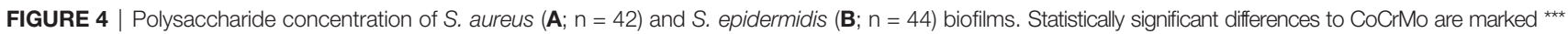
(adjusted significance $<0.001$, Bonferroni correction for the Kruskal-Wallis test).

direct comparison of CoCrMo with CoCrMo polished ( $\mathrm{p}=0.006)$, a statistically significant difference is also detected, showing a better performance (less polysaccharides) compared with biofilms grown on the polished CoCrMo surface (again no significant difference in the adj. $\mathrm{p}$-value $=0.086$ ). Overall, CoCrMo polished performs the best with respect to polysaccharide formation of biofilms.

\section{Protein Content}

Proteins in the bacterial EPS function as glue which sticks the biofilms to the surface. Measurements of proteins often employ colorimetric methods using the reduction of $\mathrm{Cu}^{2+}$ to $\mathrm{Cu}^{1+}$ copper ions in alkaline medium and compare the protein content to a bovine serum albumin (BSA) standard. Using a variation of this method (Pierce ${ }^{\mathrm{TM}}$ BCA Protein Assay Kit) we found that the highest protein levels in $S$. aureus occurred in biofilms (namely, EPS and cells) grown on CoCrMo TCP discs with a mean value of $240.08 \pm 58.6 \mu \mathrm{g} / \mathrm{ml}$. The lowest values for $S$. aureus were measured in biofilms from the CoCrMo polished discs with $96.57 \pm$ $30.8 \mu \mathrm{g} / \mathrm{ml}$ (Table 2). S. epidermidis biofilms showed the highest polysaccharide values on CoCrMo TCP as well $(215.51 \pm 56.42 \mu \mathrm{g} /$ $\mathrm{ml})$ and the lowest ones on CoCrMo polished $(76.43 \pm 30.22 \mu \mathrm{g} / \mathrm{ml})$ (Table 2). All S. aureus and all S. epidermidis biofilms from rough surfaces (CoCrMo porous coated, CoCrMo cpTi, CoCrMo TCP) have statistically significantly higher protein values $(\mathrm{p}<0.001)$ when compared to the base alloy (Figure 5). Again, all smooth surfaces have a statistically significantly better outcome compared to the rough surfaces (Table 3) when comparing them against each other separately. Additionally, in the case of $S$. aureus, CoCrMo polished and CoCrMo TiN perform statistically significantly better than CoCrMo ( $\mathrm{p}=0.004$ and $\mathrm{p}=0.005$; meaning lower protein content) in the single comparison of groups (this significance however is not applicable for the multiple comparison; $\mathrm{p}=0.058$ ), leading overall to the best performance of CoCrMo polished. For the direct group comparison of $S$. epidermidis biofilm on CoCrMo compared to CoCrMo polished (less protein) this also applies ( $\mathrm{p}=0.006$; adj $\mathrm{p}=$ 0.086 ). When considering the cpTi rough surfaces and $S$. aureus, CoCrMo cpTi results in less biofilm protein compared to CoCrMo TCP $(\mathrm{p}=0.023$; adj $\mathrm{p}=0.341)$.

TABLE 3 | Statistical pairwise comparison of alloys according to the protein and polysaccharide content of the S. aureus and S. epidermidis biofilms.

\begin{tabular}{|c|c|c|c|c|c|c|c|c|c|}
\hline \multirow[t]{3}{*}{ Alloy 1} & \multirow[t]{3}{*}{ Alloy 2} & \multicolumn{4}{|c|}{ S. aureus } & \multicolumn{4}{|c|}{ S. epidermidis } \\
\hline & & \multicolumn{2}{|c|}{ Proteins } & \multicolumn{2}{|c|}{ Polysaccharides } & \multicolumn{2}{|c|}{ Proteins } & \multicolumn{2}{|c|}{ Polysaccharides } \\
\hline & & p-value & adj. p-value & p-value & adj. p-value & $p$-value & adj. p-value & p-value & adj. p-value \\
\hline CoCrMo & CoCrMo TiN & 0.005 & 0.074 & 0.036 & 0.539 & 0.011 & 0.162 & 0.255 & 1.000 \\
\hline CoCrMo & CoCrMo polished & 0.004 & 0.058 & 0.012 & 0.178 & 0.006 & 0.086 & 0.212 & 1.000 \\
\hline CoCrMo & CoCrMo porous coated & 0.000 & 0.000 & 0.000 & 0.002 & 0.000 & 0.000 & 0.000 & 0.000 \\
\hline CoCrMo & CoCrMo cpTi & 0.000 & 0.000 & 0.000 & 0.000 & 0.000 & 0.000 & 0.000 & 0.000 \\
\hline CoCrMo & CoCrMo TCP & 0.000 & 0.000 & 0.000 & 0.005 & 0.000 & 0.000 & 0.000 & 0.000 \\
\hline CoCrMo TiN & CoCrMo polished & 0.939 & 1.000 & 0.675 & 1.000 & 0.850 & 1.000 & 0.912 & 1.000 \\
\hline CoCrMo TiN & CoCrMo porous coated & 0.000 & 0.000 & 0.000 & 0.001 & 0.000 & 0.000 & 0.000 & 0.000 \\
\hline CoCrMo TiN & CoCrMo cpTi & 0.000 & 0.000 & 0.000 & 0.000 & 0.000 & 0.000 & 0.000 & 0.000 \\
\hline CoCrMo TiN & CoCrMo TCP & 0.000 & 0.000 & 0.000 & 0.000 & 0.000 & 0.000 & 0.000 & 0.000 \\
\hline CoCrMo polished & CoCrMo porous coated & 0.000 & 0.000 & 0.000 & 0.000 & 0.000 & 0.000 & 0.000 & 0.000 \\
\hline CoCrMo polished & CoCrMo cpTi & 0.000 & 0.000 & 0.000 & 0.000 & 0.000 & 0.000 & 0.000 & 0.000 \\
\hline CoCrMo polished & CoCrMo TCP & 0.000 & 0.000 & 0.000 & 0.000 & 0.000 & 0.000 & 0.000 & 0.000 \\
\hline CoCrMo porous coated & CoCrMo cpTi & 0.042 & 0.632 & 0.006 & 0.086 & 0.076 & 1.000 & 0.004 & 0.055 \\
\hline CoCrMo porous coated & CoCrMo TCP & 0.806 & 1.000 & 0.199 & 1.000 & 0.995 & 1.000 & 0.270 & 1.000 \\
\hline CoCrMo cpTi & CoCrMo TCP & 0.023 & 0.341 & 0.139 & 1.000 & 0.077 & 1.000 & 0.072 & 1.000 \\
\hline
\end{tabular}

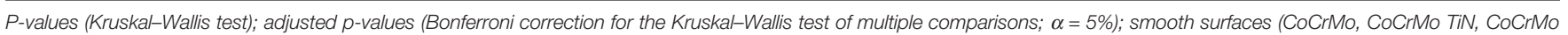
polished) underlaid in light blue; rough surfaces (CoCrMo porous coated, CoCrMo cpTi, CoCrMo TCP) underlaid in gray; $p<0.05$ also marked in green. 

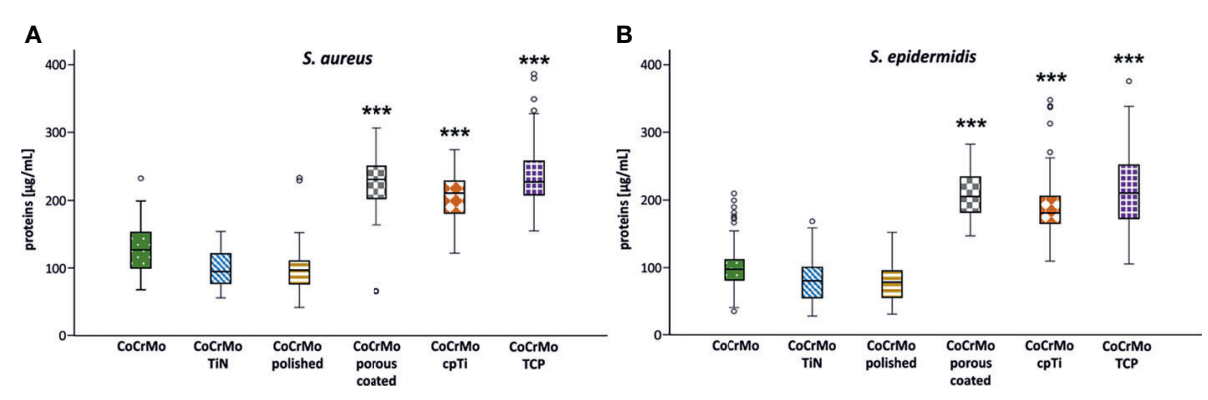

FIGURE 5 | Protein concentration of S. aureus $(\mathbf{A} ; \mathrm{n}=42)$ and S. epidermidis $(\mathbf{B} ; \mathrm{n}=44)$ biofilms. Statistically significant differences to CoCrMo are marked ${ }^{\star * \star}$ (adjusted significance $<0.001$, Bonferroni correction for the Kruskal-Wallis test).

\section{Flow Cytometric Cell Enumeration}

Flow cytometric measurements on the samples were meant to show a live-dead count. However, it seems that within $48 \mathrm{~h}$ of growth, the dead cell count is negligible which is why the flow cytometry data are only used for cell enumeration. For both species no statistical differences in the number of bacterial cells have been detected (Figure 6).

\section{RT-qPCR}

Many genes are involved in the biofilm development of $S$. aureus and S. epidermidis. A few of them have been chosen to understand the genetic reaction of both species to the different CoCrMo surfaces. Again, the different surface modifications were statistically compared to the base alloy in terms of gene expression levels of the biofilms harvested after $48 \mathrm{~h}$ of development (Figure 7). For S. aureus, icaA, and icaC were selected from the intercellular adhesion group of genes (ica) which is of specific interest for the starting phase in biofilm development. Only CoCrMo TCP showed a significantly decreased level of gene expression for both genes (Figures 7A, B). Looking at the fibronectin binding protein $f n b \mathrm{~A}$ gene, our data also shows a significantly increased level for CoCrMo TCP biofilms. However, the closely connected $f n b \mathrm{~B}$ was significantly elevated only in CoCrMo TiN. The clfB (bacterial ligand clumping factor) gene of $S$. aureus was, with $\mathrm{p}<0.05$, decreased in CoCrMo TCP, whereas the major autolysine gene ( $a t l$ ) showed no significant changes in any of the surface modification biofilms of $S$. aureus. Of the two genes tested for $S$. epidermidis, the major autolysine (atlE) also did not show any differences. However, the expression of the aap (accumulation association protein) gene was significantly reduced in CoCrMo porous coated and CoCrMo cpTi, but interestingly, not in the third rough surface modification CoCrMo TCP which showed elevated levels (not significant).

\section{DISCUSSION}

Biofilm evaluation begins with the organisms chosen for the experiment. S. aureus and S. epidermidis are the most common causes of periprosthetic infections and have therefor been the model organisms for this study. But also, within the S. aureus and
S. epidermidis isolates, differences in biofilm forming abilities exist, making it difficult to generalize results. S. aureus Newman has already been used for many studies on biofilm formation (e.g., Johnson et al., 2008; Abraham and Jefferson, 2012; Forson et al., 2020; Inés Molina et al., 2020; Pinto et al., 2020) although it is not considered a very good biofilm forming strain and the same is true for the ica negative S. epidermidis strain (e.g., Stepanovic et al., 2000; Lee et al., 2016; Paduszynska et al., 2019; Di Pilato et al., 2020; Paulitsch-Fuchs et al., 2021). However, the variant of the $S$. aureus strain used in this study $S$. aureus Newman D2C is considered to be a relatively good biofilm forming strain (Grundmeier et al., 2004; Tsompanidou et al., 2010; Abraham and Jefferson, 2012; Dauros-Singorenko et al., 2020; Paulitsch-Fuchs et al., 2021). Abraham and Jefferson (2012) showed that the autolysin activity in the Newman D2C variant was low enough to allow the expression of ClfB on the cell surface, which seems to be (at least partly) responsible for the difference in biofilm forming abilities between the two strains. The issue about different $S$. aureus Newman strains deposited to the reference centers with similar names and therefore leading to seemingly controversial results has also already been pointed out, e.g., by Grundmeier et al. (2004). It also has been shown previously (Dauros-Singorenko et al., 2020) that the D2C Newman strain expresses the agr (accessory gene regulation) quorum sensing system, which would normally mean that the dispersion in biofilms takes place rather easily (Paulander et al., 2018). However the LB medium we used is iron-rich (AbdulTehrani et al., 1999) and high iron contents did show a negative influence on agr expression in the hemoglobin study by DaurosSingorenko et al. (2020), therefore possibly promoting biofilm formation of $S$. aureus Newman D2C in LB medium. This leads to another main influence on biofilm growth which is the medium used for the experiments. Several studies compared different growth media and their influence on the biofilm formation of $S$. aureus and other species (Del mar Cendra et al., 2019; Wijesinghe et al., 2019; Zhou et al., 2019; Liu et al., 2020). For example, in one study LB medium showed the second best performance for biofilm formation in Pseudomonas aeruginosa and S. aureus (Zhou et al., 2019), in another study (Del mar Cendra et al., 2019) LB medium also promoted the biofilm growth for $S$. aureus Newman (although the wildtype strain was used). A variety of differences exist also for LB 

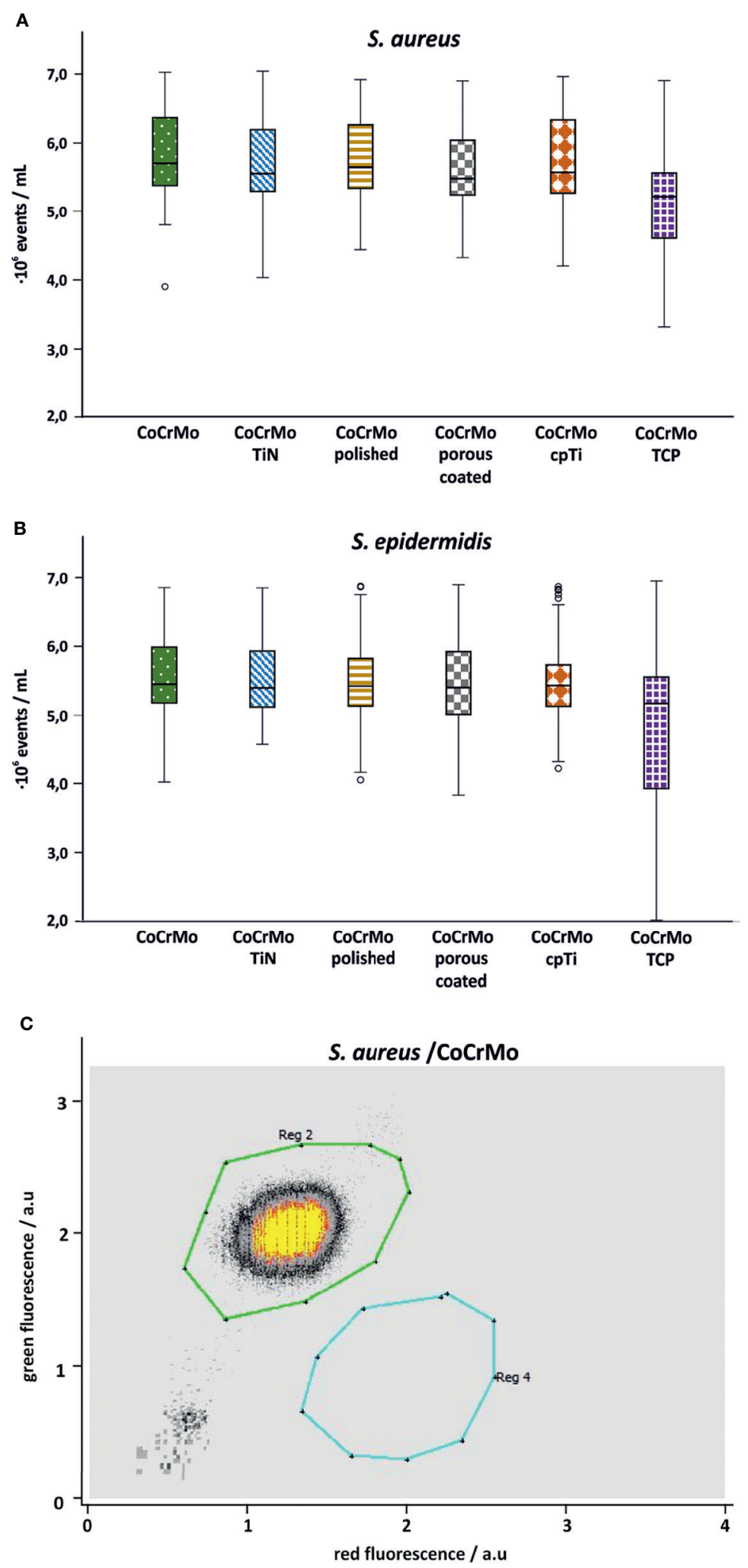

FIGURE 6 | Flow cytometry cell counts for $S$. aureus $(\mathbf{A} ; n=42)$ and $S$. epidermidis $(\mathbf{B} ; n=44)$. Subpanel $\mathbf{( C )}$ shows a representative measurement of $S$. aureus on CoCrMo (Reg 2: living cells; Reg 4: dead cells). 

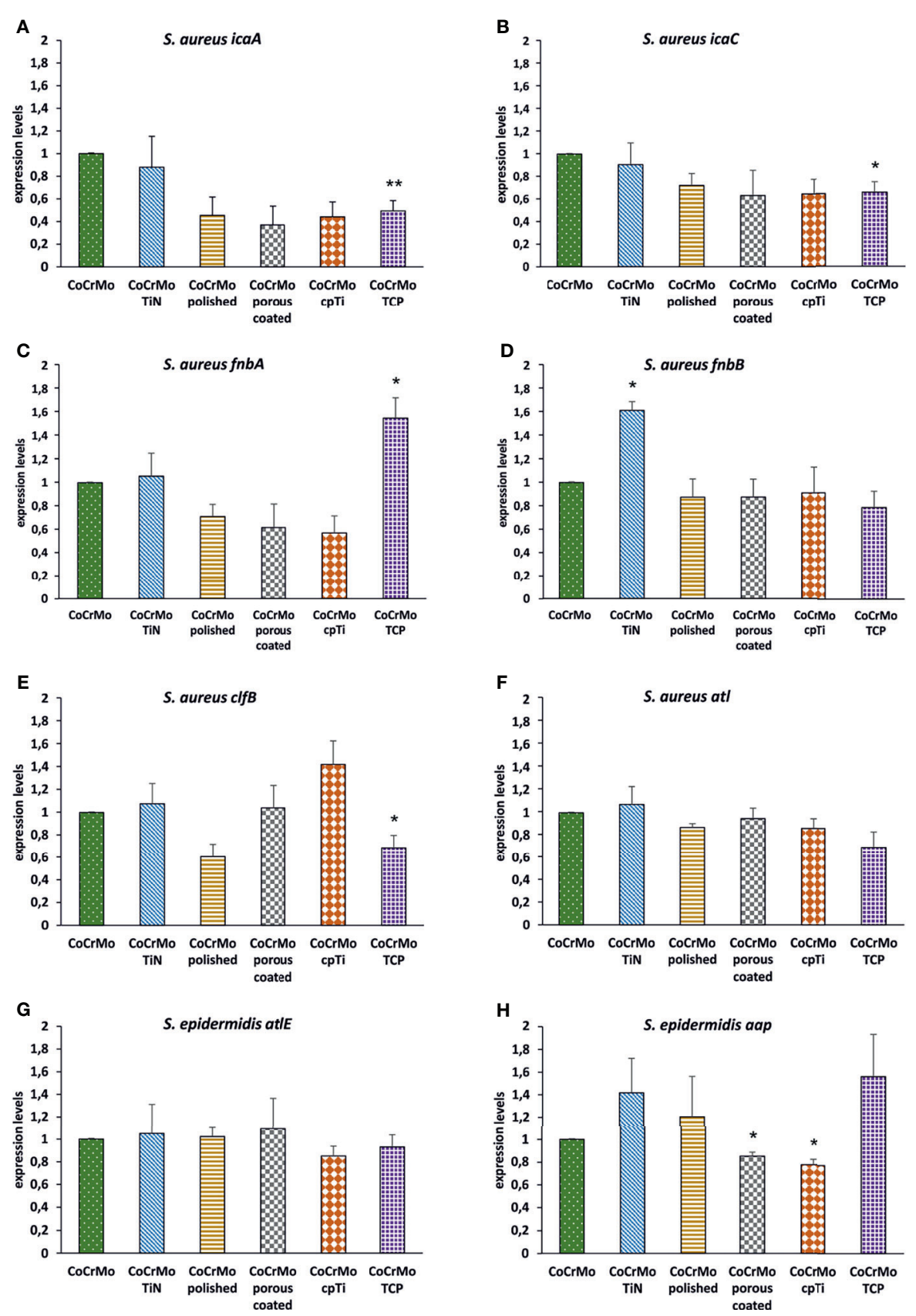

FIGURE 7 | Expression levels of biofilm-associated genes. S. aureus $(\mathbf{A}-\mathbf{F} ; n=3)$ and $S$. epidermidis $(\mathbf{G}, \mathbf{H} ; \mathrm{n}=3)$; error bars show the standard error of the mean; statistically significant differences to CoCrMo are marked * $(p<0.05)$.

medium recipes (e.g., supplemented with glucose, higher or lower $\mathrm{NaCl}$ content) and most other growth media. Lastly also the number of bacterial cells inoculated for biofilm formation varies greatly in the different studies on this topic. As little as $\mathrm{OD}_{550}$ of $0.10\left(\sim 0.015 \times 10^{7}\right.$ cells $\left./ \mathrm{ml}\right)$ (Del mar Cendra et al., 2019) and also higher cell numbers of $1 \times 10^{7} \mathrm{CFU} / \mathrm{ml}$ (DaurosSingorenko et al., 2020) and inoculum sizes using 0.5 MacFarland cell suspensions $\left(1.5 \times 10^{8}\right.$ cells/ml) (Wijesinghe et al., 2019) are implemented for biofilm studies. Therefore, the choice of the strains, inoculum size and media used in biofilm studies has to be well thought of.

Although the interaction of biofilms with the respected surfaces they grown on is a key factor as well, still understanding is lacking in some areas of this interaction, e.g., the influence of surface roughness on biofilm development and its connection to the regulation of genes connected to biofilm formation. For an 
TABLE 4 | Overall comparison of the results of protein, polysaccharide and genetic measurements.

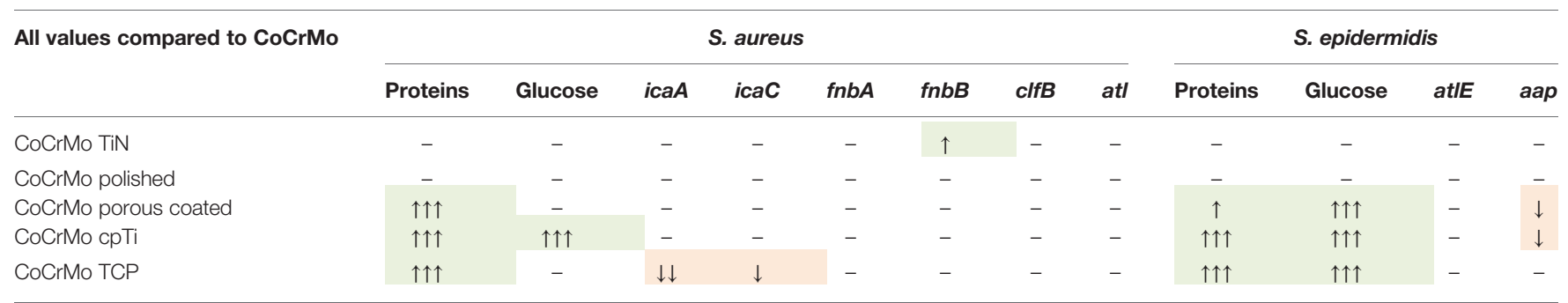

$\uparrow, \uparrow \uparrow$ and $\uparrow \uparrow \uparrow$ (also underlaid in green; adjusted significance $<0.05,<0.01$ and 0.001 according to the Bonferroni correction for the Kruskal-Wallis test) and $\downarrow$, and $\downarrow \downarrow$ (also underlaid in orange; adjusted significance $<0.05$ and $<0.01$ according to the Bonferroni correction for the Kruskal-Wallis test).

overview and to facilitate this connection, Table 4 provides an overall comparison of protein, polysaccharide and gene expression results.

The surfaces studied here vary widely in their surface characteristics and structure (see Figure 2), thus providing a good variety of roughness for biofilm formation observations. Both protein and polysaccharide measurements are valuable measurements for the understanding of bacterial adherence and biofilm compactness in later stages of biofilm development. While host-proteins play an important role in the early conditioning of the implant thus strengthening the incorporation of the implant (Wang et al., 2017), proteins of biofilm organisms use the same properties to attach to the material in early biofilm development. Polysaccharides are important surface characteristics of bacterial cells and contribute to EPS development and to the attachment of bacterial cells to surfaces and to each other (Limoli et al., 2015). We show that the surface modifications resulting in rough surfaces (CoCrMo porous coated, CoCrMo cpTi, and CoCrMo TCP) have a higher polysaccharide and protein load in the biofilms than the smooth surfaces (CoCrMo TiN, CoCrMo polished) and the untreated control (CoCrMo). In most cases this is a statistically significant difference and holds for most of the comparisons of the alloys to each other as well (see Table 3). Those results are in accordance with earlier studies on the topic (Öztürk et al., 2007; Yoda et al., 2014; Kunrath et al., 2020; Palka et al., 2020; Paulitsch-Fuchs et al., 2021), supporting the conclusion that the higher surface roughness is beneficial for protein and polysaccharide rich biofilms on the surfaces studied here. However, in a review by Zheng et al. (2021), the influence of surface structures has been recently summarized showing that generally, bacteria tend to attach to surfaces more easily when they have a certain roughness, however there are also some rough surfaces achieving the opposite and also different bacterial species can react in different ways to the same surface.

Biofilm gene regulation did not show particularly big differences between the compared groups. As no RNAlater ${ }^{\circledR}$ or comparable reagent was used to freeze the transcriptome after biofilm removal a shift in the transcriptome might have occurred during the biofilm processing steps. However, as all samples were treated in the same way the relative impact is expected to be the same on the individual samples. For S. aureus, Resch et al. (2005) reported the genes ica $A$ and $i c a C$, which are commonly involved in early biofilm development, not to be upregulated in biofilms compared to planktonic growth after $48 \mathrm{~h}$ of growth. Expression of $i c a A, i c a C$, and aap gene regulation in S. epidermidis biofilms on different materials was reported by Patel et al. (2012) still to be active after $48 \mathrm{~h}$ of biofilm development. In an earlier study we found that on different Titanium-alloy surfaces the gene expression of the same set of genes of S. aureus Newman D2C followed a similar trend (Paulitsch-Fuchs et al., 2021) in that if there was a statistical difference in the regulation it was a decrease compared to the control (which was the untreated TiAl6V4 alloy, a rather smooth surface). Atshan et al. (2013) reported for four different MRSA isolates peak values of $f n b A, f n b B$, and $c l f B$ after $24 \mathrm{~h}$. Comparing this with our results we conclude that the measurement point at $48 \mathrm{~h}$ is late into biofilm development and therefore no upregulation of the genes could be detected (with exception of fnbB on CoCrMo TiN). Together, the results point in the direction that the biofilm at $48 \mathrm{~h}$ is already well established and it is possibly not necessary that genes of early attachment are still upregulated. There is no difference in gene regulation between smooth and rough surfaces detectable at this timepoint. The $S$. epidermidis strain used in this study is icaA and icaC gene negative (this has been confirmed during this study; data not shown). As those genes are involved in the biosynthesis machinery necessary for PIA production in staphylococcal biofilms it is interesting that polysaccharides have been detected in the S. epidermidis strain which is ica negative. The explanation might be that other polysaccharide species (which are not regulated by the ica family of genes) are expressed in the strain used in this study. For example Spiliopoulou et al. (2012), have reported a $20-\mathrm{kDa}$ polysaccharide (composed of glucose and $\mathrm{N}$-acetylglucosamine) in the S. epidermidis EPS which is independent from ica. The two genes detected in the present study, atlE and aap, were both reported to be still active after $48 \mathrm{~h}$ of biofilm development by Patel et al. (2012). Similarly, the results presented here show an upregulation compared to the CoCrMo control on the smooth surfaces (not significant), the biofilms on the rough surfaces show a downregulation in at least one of the two genes after $48 \mathrm{~h}$, CoCrMo cpTi in both genes (one of them significantly lower than the control). On those rough surfaces, the amount of proteins and polysaccharides was significantly higher in all cases, indicating that single cells in biofilms on rougher surfaces are producing a higher amount of proteins and polysaccharides. Otto (2013) shows a difference between early and late maturation phase in terms of 
adhesive and disruptive factors. We speculate that the biofilms on the rough surfaces in our study do not need the atlE and aap gene products, which are involved mainly in mediation of the early attachment and in accumulation (Patel et al., 2012; Arciola et al., 2015), anymore. To prove this conclusively further studies on biofilm developmental stages are necessary.

In conclusion, the rough CoCrMo surface-modifications are prone to biofilms showing a higher amount of proteins and polysaccharides. The transcription rate of the genes studied here needs to be studied at different time points in order to draw a hard conclusion as to the impact of surfaces on the regulation of those genes. Follow-up studies therefore should include more time points, defined biofilm forming strains and clinical isolates for gene analysis in order to get a better understanding of timedependent development. In addition, a study of human osteoblast cell cultures and bacterial cells being co-incubated on the surfaces might provide insights in the competition for the place on the surfaces.

\section{DATA AVAILABILITY STATEMENT}

The original contributions presented in the study are included in the article/supplementary material. Further inquiries can be directed to the corresponding author.

\section{REFERENCES}

Abdul-Tehrani, H., Hudson, A. J., Chang, Y. S., Timms, A. R., Hawkins, C., Williams, J. M., et al. (1999). Ferritin Mutants of Escherichia Coli Are Iron Deficient and Growth Impaired, and Fur Mutants are Iron Deficient. J. Bacteriol. 181, 1415. doi: 10.1128/jb.181.5.1415-1428.1999

Abraham, N. M., and Jefferson, K. K. (2012). Staphylococcus Aureus Clumping Factor B Mediates Biofilm Formation in the Absence of Calcium. Microbiology 158, 1504. doi: 10.1099/MIC.0.057018-0

Arciola, C. R., Campoccia, D., Ravaioli, S., and Montanaro, L. (2015). Polysaccharide Intercellular Adhesin in Biofilm: Structural and Regulatory Aspects. Front. Cell. Infect. Microbiol. 5. doi: 10.3389/fcimb.2015.00007

Atshan, S. S., Shamsudin, M. N., Karunanidhi, A., van Belkum, A., Lung, L. T. T., Sekawi, Z., et al. (2013). Quantitative PCR Analysis of Genes Expressed During Biofilm Development of Methicillin Resistant Staphylococcus Aureus (MRSA). Infect. Genet. Evol. 18, 106-112. doi: 10.1016/j.meegid.2013.05.002

Chen, Q., and Thouas, G. A. (2015). Metallic Implant Biomaterials. Mater. Sci. Eng. R Rep. 87, 1-57. doi: 10.1016/j.mser.2014.10.001

Cuesta, G., Suarez, N., Bessio, M. I., Ferreira, F., and Massaldi, H. (2003). Quantitative Determination of Pneumococcal Capsular Polysaccharide Serotype 14 Using a Modification of Phenol-Sulfuric Acid Method. J. Microbiol. Methods 52, 69-73. doi: 10.1016/S0167-7012(02)00151-3

Dantas, T. A., Costa, M. M., Miranda, G., Silva, F. S., Abreu, C. S., and Gomes, J. R. (2018). Effect of HAp and $\beta$-TCP Incorporation on the Tribological Response of Ti6Al4V Biocomposites for Implant Parts. J. Biomed. Mater. Res. - Part B Appl. Biomater. 106, 1010-1016. doi: 10.1002/jbm.b.33908

Dauros-Singorenko, P., Wiles, S., and Swift, S. (2020). Staphylococcus Aureus Biofilms and Their Response to a Relevant In Vivo Iron Source. Front. Microbiol. 11. doi: 10.3389/FMICB.2020.509525/FULL

Davis, J. R. (2003). “Overview of Biomaterials and Their Use in Medical Devices," in Handbook of Materials for Medical Devices Russell Township (in Ohio, USA): ASM International. Ed. J. R. Davis. Russell Township (in Ohio, USA): ASM International. 1-11. doi: 10.1361/hmmd2003p001

Del mar Cendra, M., Blanco-Cabra, N., Pedraz, L., and Torrents, E. (2019). Optimal Environmental and Culture Conditions Allow the In Vitro

\section{AUTHOR CONTRIBUTIONS}

A.P-F.: Conceptualization, Methodology, Validation, Visualization, Supervision, Writing-Original Draft, WritingReview \& Editing, Project administration. B.B.: Investigation, Formal analysis, Writing Original Draft. L.W.: Investigation, Formal analysis, Visualization. N.D.: Statistical Assessment, Rewriting and Editing. N.E.: Investigation, Formal Analysis. B.L.: Funding acquisition, Project administration, Supervision, Writing-Review \& Editing. All authors listed have made a substantial, direct, and intellectual contribution to the work and approved it for publication.

\section{FUNDING}

The authors acknowledge financial support from the FFG Bridge program (Grant No. 861608).

\section{ACKNOWLEDGMENTS}

We would like to thank our co-workers at the respective laboratories for their support concerning laboratory organization and the fruitful discussions.

Coexistence of Pseudomonas Aeruginosa and Staphylococcus Aureus in Stable Biofilms. Sci. Rep. 9, 1-17. doi: 10.1038/s41598-019-52726-0

Di Pilato, V., Ceccherini, F., Sennati, S., D’Agostino, F., Arena, F., D’Atanasio, N., et al. (2020). In Vitro Time-Kill Kinetics of Dalbavancin Against Staphylococcus Spp. Biofilms Over Prolonged Exposure Times. Diagn. Microbiol. Infect. Dis. 96, 114901. doi: 10.1016/J.DIAGMICROBIO.2019.114901

Forson, A. M., van der Mei, H. C., and Sjollema, J. (2020). Impact of Solid Surface Hydrophobicity and Micrococcal Nuclease Production on Staphylococcus Aureus Newman Biofilms. Sci. Rep. 10, 1-10. doi: 10.1038/S41598-02069084-X

Geetha, M., Singh, A. K., Asokamani, R., and Gogia, A. K. (2009). Ti Based Biomaterials, the Ultimate Choice for Orthopaedic Implants - A Review. Prog. Mater. Sci. 54, 397-425. doi: 10.1016/j.pmatsci.2008.06.004

Grundmeier, M., Hussain, M., Becker, P., Heilmann, C., Peters, G., and Sinha, B. (2004). Truncation of Fibronectin-Binding Proteins in Staphylococcus Aureus Strain Newman Leads to Deficient Adherence and Host Cell Invasion Due to Loss of the Cell Wall Anchor Function. Infect. Immun. 72, 7155-7163. doi: 10.1128/IAI.72.12.7155-7163.2004

Idrees, M., Sawant, S., Karodia, N., and Rahman, A. (2021). Staphylococcus Aureus Biofilm: Morphology, Genetics, Pathogenesis and Treatment Strategies. Int. J. Environ. Res. Public Heal. 18, 7602 18, 7602. doi: 10.3390/ IJERPH18147602

Inés Molina, R. D., Campos-Silva, R., Díaz, M. A., Macedo, A. J., Blázquez, M. A., Alberto, M. R., et al. (2020). Laurel Extracts Inhibit Quorum Sensing, Virulence Factors and Biofilm of Foodborne Pathogens. LWT 134, 109899. doi: 10.1016/ J.LWT.2020.109899

ISO ISO 13779-2:2018 - Implants for Surgery - Hydroxyapatite - Part 2: Thermally Sprayed Coatings of Hydroxyapatite. Available at: https://www.iso. org/standard/64617.html (Accessed September 7, 2021).

ISO ISO 5832-2:2018 - Implants for Surgery - Metallic Materials - Part 2: Unalloyed Titanium. Available at: https://www.iso.org/standard/69907.html (Accessed September 3, 2021).

ISO ISO 5832-3:2016 - Implants for Surgery - Metallic Materials - Part 3: Wrought Titanium 6-Aluminium 4-Vanadium Alloy. Available at: https:// www.iso.org/standard/66637.html (Accessed May 16, 2021). 
ISO ISO 6892-1:2019(En), Metallic Materials - Tensile Testing - Part 1: Method of Test at Room Temperature. Available at: https://www.iso.org/obp/ui/ \#iso:std:iso:6892:-1:ed-3:v1:en (Accessed May 16, 2021).

Johnson, M., Cockayne, A., and Morrissey, J. A. (2008). Iron-Regulated Biofilm Formation in Staphylococcus Aureus Newman Requires Ica and the Secreted Protein Emp. Infect. Immun. 76, 1756. doi: 10.1128/IAI.01635-07

Kavanaugh, J. S., and Horswill, a. R. (2016). Impact of Environmental Cues on Staphylococcal Quorum Sensing and Biofilm Development. J. Biol. Chem. 291, 12556-12564. doi: 10.1074/jbc.R116.722710

Kim, M. K., Zhao, A., Wang, A., Brown, Z. Z., Muir, T. W., Stone, H. A., et al. (2017). Surface-Attached Molecules Control Staphylococcus Aureus Quorum Sensing and Biofilm Development. Nat. Microbiol. 2, 17080. doi: 10.1038/ NMICROBIOL.2017.80

Kunrath, M. F., Monteiro, M. S. G., Gupta, S., Hubler, R., and de Oliveira, S. D. (2020). Influence of Titanium and Zirconia Modified Surfaces for Rapid Healing on Adhesion and Biofilm Formation of Staphylococcus Epidermidis. Arch. Oral. Biol. 117, 104824. doi: 10.1016/J.ARCHORALBIO.2020.104824

Lamret, F., Colin, M., Mongaret, C., Gangloff, S. C., and Reffuveille, F. (2020). Antibiotic Tolerance of Staphylococcus Aureus Biofilm in Periprosthetic Joint Infections and Antibiofilm Strategies. Antibiot 9, 547 9, 547. doi: 10.3390/ ANTIBIOTICS9090547

Lee, J. H., Kim, Y. G., Yong Ryu, S., and Lee, J. (2016). Calcium-Chelating Alizarin and Other Anthraquinones Inhibit Biofilm Formation and the Hemolytic Activity of Staphylococcus Aureus. Sci. Rep. 201661 6, 1-11. doi: 10.1038/srep19267

Limoli, D. H., Jones, C. J., and Wozniak, D. J. (2015). Bacterial Extracellular Polysaccharides in Biofilm Formation and Function. Microbiol. Spectr. 3, 1-19. doi: 10.1128/MICROBIOLSPEC.MB-0011-2014

Liu, Y., Zhang, J., and Ji, Y. (2020). Environmental Factors Modulate Biofilm Formation by Staphylococcus Aureus. Sci. Prog. 103, 36850419898659. doi: $10.1177 / 0036850419898659$

Livak, K. J., and Schmittgen, T. D. (2001). Analysis of Relative Gene Expression Data Using Real-Time Quantitative PCR and the 2- $\Delta \Delta \mathrm{CT}$ Method. Methods 25, 402-408. doi: 10.1006/meth.2001.1262

Lohberger, B., Eck, N., Glaenzer, D., Lichtenegger, H., Ploszczanski, L., and Leithner, A. (2020a). Cobalt Chromium Molybdenum Surface Modifications Alter the Osteogenic Differentiation Potential of Human Mesenchymal Stem Cells. Materials (Basel) 13, 1-14. doi: 10.3390/ma13194292

Lohberger, B., Stuendl, N., Glaenzer, D., Rinner, B., Donohue, N., Lichtenegger, H. C., et al. (2020b). CoCrMo Surface Modifications Affect Biocompatibility, Adhesion, and Inflammation in Human Osteoblasts. Sci. Rep. 10, 1-8. doi: 10.1038/s41598-020-58742-9

Munir, K., Biesiekierski, A., Wen, C., and Li, Y. (2020). "Surface Modifications of Metallic Biomaterials,". In: Metallic Biomaterials Processing and Medical Device Manufacturing, ed. C. Wen (Cambridge, MA: Elsevier), 387-424. doi: 10.1016/ b978-0-08-102965-7.00012-6

Otto, M. (2013). Staphylococcal Infections: Mechanisms of Biofilm Maturation and Detachment as Critical Determinants of Pathogenicity. Annu. Rev. Med. 64, 175-188. doi: 10.1146/annurev-med-042711-140023

Öztürk, O., Sudagidan, M., and Türkan, U. (2007). Biofilm Formation by Staphylococcus Epidermidis on Nitrogen Ion Implanted CoCrMo Alloy Material. J. Biomed. Mater. Res. A 81, 663-668. doi: 10.1002/JBM.A.31037

Paduszynska, M. A., Maciejewska, M., Neubauer, D., Golacki, K., Szymukowicz, M., Bauer, M., et al. (2019). Influence of Short Cationic Lipopeptides With Fatty Acids of Different Chain Lengths on Bacterial Biofilms Formed on Polystyrene and Hydrogel Surfaces. Pharm 11, 506 11, 506. doi: 10.3390/PHARMACEUTICS11100506

Palka, L., Mazurek-Popczyk, J., Arkusz, K., and Baldy-Chudzik, K. (2020). Susceptibility to Biofilm Formation on 3D-Printed Titanium Fixation Plates Used in the Mandible: A Preliminary Study. J. Oral. Microbiol. 12, 1-12. doi: 10.1080/20002297.2020.1838164

Palsis, J. A., Brehmer, T. S., Pellegrini, V. D., Drew, J. M., and Sachs, B. L. (2018). The Cost of Joint Replacement Comparing Two Approaches to Evaluating Costs of Total Hip and Knee Arthroplasty. J. Bone Jt. Surg. - Am. 100, 326-333. doi: 10.2106/JBJS.17.00161

Patel, J. D., Colton, E., Ebert, M., and Anderson, J. M. (2012). Gene Expression During S. Epidermidis Biofilm Formation on Biomaterials. J. Biomed. Mater. Res. - Part A 100 A, 2863-2869. doi: 10.1002/jbm.a.34221
Paulander, W., Varming, A. N., Bojer, M. S., Friberg, C., Bæk, K., and Ingmer, H. (2018). The Agr Quorum Sensing System in Staphylococcus Aureus Cells Mediates Death of Sub-Population. BMC Res. Notes 11, 503. doi: 10.1186/ S13104-018-3600-6

Paulitsch-Fuchs, A. H., Wolrab, L., Eck, N., Dyer, N. P., Bödendorfer, B., and Lohberger, B. (2021). TiAl6V4 Alloy Surface Modifications and Their Impact on Biofilm Development of S. Aureus and S. Epidermidis. J. Funct. Biomater. 12, 36. doi: $10.3390 / \mathrm{jfb} 12020036$

Phillips, J. E., Crane, T. P., Noy, M., Elliott, T. S. J., and Grimer, R. J. (2006). The Incidence of Deep Prosthetic Infections in a Specialist Orthopaedic Hospital A 15-YEAR PROSPECTIVE SURVEY. J. Bone Jt. Surg. [Br] 88, 943-951. doi: 10.1302/0301-620X.88B7

Pinto, H. B., Brust, F. R., Macedo, A. J., and Trentin, D. S. (2020). The Antivirulence Compound Myricetin Possesses Remarkable Synergistic Effect With Antibacterials Upon Multidrug Resistant Staphylococcus Aureus. Microb. Pathog. 149, 104571. doi: 10.1016/j.micpath.2020.104571

Resch, A., Rosenstein, R., Nerz, C., and Go, F. (2005). Differential Gene Expression Profiling of Staphylococcus aureus Cultivated under Biofilm and Planktonic Conditions. Appl. Environ. Microbiol. 71, 2663-2676. doi: 10.1128/ AEM.71.5.2663

Rupp, M., Lau, E., Kurtz, S. M., and Alt, V. (2020). Projections of Primary TKA and THA in Germany From 2016 Through 2040. Clin. Orthop. Relat. Res. 478, 1622. doi: 10.1097/CORR.0000000000001214

Ryder, V. J., Chopra, I., and O'Neill, A. J. (2012). Increased Mutability of Staphylococci in Biofilms as a Consequence of Oxidative Stress. PloS One 7, e47695. doi: 10.1371/JOURNAL.PONE.0047695

Shoji, M. M., and Chen, A. F. (2020). Biofilms in Periprosthetic Joint Infections: A Review of Diagnostic Modalities, Current Treatments, and Future Directions. J. Knee Surg. 33, 119-131. doi: 10.1055/s-0040-1701214

Singh, R., Ray, P., Das, A., and Sharma, M. (2010). Penetration of Antibiotics Through Staphylococcus Aureus and Staphylococcus Epidermidis Biofilms. J. Antimicrob. Chemother. 65, 1955-1958. doi: 10.1093/jac/dkq257

Sloan, M., Premkumar, A., and Sheth, N. P. (2018). Projected Volume of Primary Total Joint Arthroplasty in the U.s. 2014 to 2030. J. Bone Jt. Surg. - Am. Vol. 100, 1455-1460. doi: 10.2106/JBJS.17.01617

Spiliopoulou, A. I., Krevvata, M. I., Kolonitsiou, F., Harris, L. G., Wilkinson, T. S., Davies, A. P., et al. (2012). An Extracellular Staphylococcus Epidermidis Polysaccharide: Relation to Polysaccharide Intercellular Adhesin and its Implication in Phagocytosis. BMC Microbiol. 12, 1-15. doi: 10.1186/14712180-12-76/TABLES/3

Stepanovic, S., Vukovic, D., Dakic, I., Savic, B., and Svabic-Vlahovic, M. (2000). A Modified Microtiter-Plate Test for Quantification of Staphylococcal Biofilm Formation. J. Methods Microbiol. J. Microbiol. Methods 40, 175-179. doi: 10.1016/S0167-7012(00)00122-6

Thomas, P., Weik, T., Roider, G., Summer, B., and Thomsen, M. (2016). Influence of Surface Coating on Metal Ion Release: Evaluation in Patients With Metal Allergy. Orthopedics 39, S24-S30. doi: 10.3928/01477447-20160509-08

Tsaras, G., Osmon, D. R., Mabry, T., Lahr, B., Sauveur, J., Yawn, B., et al. (2012). Incidence, Secular Trends, and Outcomes of Prosthetic Joint Infection: A Population-Based Study, Olmsted County, Minnesota 1969-2007. Infect. Control Hosp. Epidemiol. 33, 1207-1212. doi: 10.1086/668421

Tsompanidou, E., Sibbald, M. J. J. B., Chlebowicz, M. A., Dreisbach, A., Back, J. W., Van Dijl, J. M., et al. (2010). Requirement of the Agr Locus for Colony Spreading of Staphylococcus Aureus. J. Bacteriol. 193, 1267-1272. doi: 10.1128/ JB.01276-10

Vandecasteele, S. J., Peetermans, W. E., Merckx, R., and Van Eldere, J. (2001). Quantification of Expression of Staphylococcus Epidermidis Housekeeping Genes With Taqman Quantitative PCR During In Vitro Growth and Under Different Conditions. J. Bacteriol. 183, 7094. doi: 10.1128/JB.183.24.70947101.2001

Van Hove, R. P., Sierevelt, I. N., Van Royen, B. J., and Nolte, P. A. (2015). Titanium-Nitride Coating of Orthopaedic Implants: A Review of the Literature. BioMed. Res. Int. 2015, 1-9. doi: 10.1155/2015/485975

Venter, H., Bui, L. M. G., Conlon, B. P., and Kidd, S. P. (2017). Antibiotic Tolerance and the Alternative Lifestyles of Staphylococcus Aureus. Essays Biochem. 61, 71-79. doi: 10.1042/EBC20160061 
Wang, Z., Yan, Y., and Qiao, L. (2017). Protein Adsorption on Implant Metals With Various Deformed Surfaces. Colloids Surfaces B Biointerfaces 156, 62-70. doi: 10.1016/j.colsurfb.2017.05.015

Wijesinghe, G., Dilhari, A., Gayani, B., Kottegoda, N., Samaranayake, L., and Weerasekera, M. (2019). Influence of Laboratory Culture Media on In Vitro Growth, Adhesion, and Biofilm Formation of Pseudomonas Aeruginosa and Staphylococcus Aureus. Med. Princ. Pract. 28, 28. doi: 10.1159/000494757

Yin, S., Jiang, B., Huang, G., Zhang, Y., You, B., Chen, Y., et al. (2018). The Interaction of N-Acetylcysteine and Serum Transferrin Promotes Bacterial Biofilm Formation. Cell. Physiol. Biochem. 45, 1399-1409. doi: 10.1159/000487566

Yoda, I., Koseki, H., Tomita, M., Shida, T., Horiuchi, H., Sakoda, H., et al. (2014). Effect of Surface Roughness of Biomaterials on Staphylococcus Epidermidis Adhesion. BMC Microbiol. 14, 1-7. doi: 10.1186/s12866-014-0234-2

Zheng, S., Bawazir, M., Dhall, A., Kim, H. E., He, L., Heo, J., et al. (2021). Implication of Surface Properties, Bacterial Motility, and Hydrodynamic Conditions on Bacterial Surface Sensing and Their Initial Adhesion. Front. Bioeng. Biotechnol. 9. doi: 10.3389/FBIOE.2021.643722

Zhou, G., Peng, H., Wang, Y. S., Huang, X. M., Xie, X. B., and Shi, Q. S. (2019). Enhanced Synergistic Effects of Xylitol and Isothiazolones for Inhibition of Initial Biofilm Formation by Pseudomonas Aeruginosa ATCC 9027 and Staphylococcus Aureus ATCC 6538. J. Oral. Sci. 61, 255-263. doi: 10.2334/JOSNUSD.18-0102
Zimmerli, W., Lew, P. D., and Waldvogel, F. A. (1984). Pathogenesis of Foreign Body Infection. Evidence for a Local Granulocyte Defect. J. Clin. Invest. 73, 1191-1200. doi: 10.1172/JCI111305

Conflict of Interest: The authors declare that the research was conducted in the absence of any commercial or financial relationships that could be construed as a potential conflict of interest.

Publisher's Note: All claims expressed in this article are solely those of the authors and do not necessarily represent those of their affiliated organizations, or those of the publisher, the editors and the reviewers. Any product that may be evaluated in this article, or claim that may be made by its manufacturer, is not guaranteed or endorsed by the publisher.

Copyright (C) 2022 Paulitsch-Fuchs, Bödendorfer, Wolrab, Eck, Dyer and Lohberger. This is an open-access article distributed under the terms of the Creative Commons Attribution License (CC BY). The use, distribution or reproduction in other forums is permitted, provided the original author(s) and the copyright owner(s) are credited and that the original publication in this journal is cited, in accordance with accepted academic practice. No use, distribution or reproduction is permitted which does not comply with these terms. 